\title{
“PARECE UM PREZINHO”: FAMÍLIAS DE CLASSES POPULARES E O NOVO ENSINO FUNDAMENTAL
}

\author{
Maria Silvia Pinto de Moura Librandi da Rocha*
}

\begin{abstract}
RESUMO. Este artigo aborda parte dos resultados de pesquisa desenvolvida em 8 turmas de primeiro ano de 5 escolas municipais, visando estudar a implementação do Ensino Fundamental (EF) de 9 anos. Desenvolvida em 2006 - ano de adoção do novo EF no município em que as escolas se encontram - a pesquisa compôs-se por conjunto de procedimentos metodológicos, dos quais destacamos as entrevistas semi-estruturadas com 58 familiares de alunos de 6 anos das turmas estudadas. As análises do material empírico permitiram evidenciar que a recepção do novo EF pelos entrevistados foi predominantemente favorável, decorrente de expectativas de alfabetização das crianças. Consequentemente, avaliaram de modo positivo atividades de leitura/escrita no primeiro ano, criticaram a baixa frequiência das mesmas no cotidiano escolar e opuseram-se à existência de outras atividades no currículo, sobretudo às atividades lúdicas. Com este estudo, pretende-se contribuir para reflexões sobre desafios a serem enfrentados na implementação do novo EF, focalizando, particularmente, as relações famílias-escolas.
\end{abstract}

Palavras-chave: Ensino fundamental de 9 anos; avaliação das práticas pedagógicas; relações família-escola.

\section{“IT LOOKS LIKE A KINDERGARTEN”: LOW-INCOME FAMILIES AND THE NEW ELEMENTARY TEACHING}

\begin{abstract}
This article relates to part of the results of a research developed in 8 first year classes of 5 city-funded schools, with the objective of studying the implementation of nine year Elementary Teaching (ET). Developed in 2006 - the year the new ET in the city-funded schools was adopted - the research was composed of a group of methodological procedures, the main focus of which will be semi-structured interviews with 58 relatives of six-year old students of those classes studied. The analysis of the empirical material revealed that the acceptance of the new ET by those interviewed was predominantly favorable, according to the expectation of a child's reading/writing process. Consequently, they evaluated in a positive way the reading/writing activities, criticized their low occurrence and were against other activities in the curriculum, especially games. The aim of this study is to contribute to reflections on challenges to be faced in the implementation of the new ET, focusing specifically on family-school relationships.
\end{abstract}

Key words: 9 year Elementary Teaching; pedagogical procedure evaluation; family-school relationships.

\section{“PARECE UNA CUNA”: FAMILIAS DE CLASES POPULARES Y LA NUEVA ENSEÑANZA FUNDAMENTAL}

RESUMEN. Este artículo aborda parte de los resultados de las investigaciones desarrolladas con 8 grupos de primer año, de 5 escuelas municipales, con el objetivo de estudiar el proceso de implementación de la nueva Enseñanza Fundamental (EF) de 9 años. Desarrollada en 2006 - año de adopción de la nueva EF en el municipio en que se encuentran las escuelas - la investigación se basa en un conjunto de procedimientos metodológicos, de los cuales serán resaltadas las entrevistas semiestructuradas con 58 familiares de los alumnos con 6 años de edad de los grupos estudiados. Con base en las expectativas en la alfabetización de los niños, el análisis del material empírico permitió evidenciar que la recepción de la nueva EF fue predominantemente favorable, entre los entrevistados. Fueron evaluadas de modo positivo las actividades de lectura/escrita, criticándose la poca frecuencia de estas y oponiéndose a la existencia de otras actividades en el currículo, sobre todo las actividades lúdicas. Con este estudio se pretende contribuir a la reflexión sobre los desafíos a ser enfrentados en la implementación de la nueva $\mathrm{EF}$, focalizando particularmente, la relación familia-escuela.

Palabras-clave: Enseñanza fundamental de 9 años; evaluación de prácticas pedagógicas; relación familia-escuela.

Psicóloga. Doutorado em Educação pela Universidade Estadual de Campinas. Atualmente é docente do Programa de PósGraduação em Educação da Pontifícia Universidade Católica de Campinas 
Este artigo aborda parte dos resultados de uma pesquisa realizada para estudar a implementação do Ensino Fundamental de 9 anos, oficializado pela promulgação da lei federal $n^{\circ} 11.274$ (ocorrida em 06 de fevereiro de 2006). Embora as determinações federais indicassem que o novo Ensino Fundamental poderia ser implantado até o ano de 2010, a Secretaria de Educação do município em que a pesquisa foi desenvolvida (uma cidade de grande porte do interior do Estado de São Paulo), optou por fazê-lo já em 2006. O trabalho de campo foi desenvolvido neste primeiro ano de implantação, em 8 turmas de 5 escolas municipais, com delineamento metodológico inspirado na etnografia e se apoiou num conjunto de procedimentos: observações participantes semanais do cotidiano escolar, entrevistas semi-estruturadas com as professoras, alunos e algum adulto responsável pelas crianças, questionários respondidos por orientadoras pedagógicas da Educação Infantil (EI) e análise documental das publicações do MEC sobre o Ensino Fundamental de 9 anos. No presente texto, será focalizado o material empírico construído a partir das entrevistas semi-estruturadas feitas com algum membro adulto das famílias das crianças matriculadas, em 2006, no primeiro ano do Ensino Fundamental (EF). Com as análises produzidas, pretende-se oferecer contribuições para reflexões sobre os desafios a serem enfrentados na implementação do EF de 9 anos, sobretudo dando visibilidade aos modos como estes adultos compreenderam e avaliaram a proposta pedagógica em foco. Pretende-se, ainda gerar material que fundamente discussões futuras sobre quais os efeitos desta compreensão e avaliação para o trabalho pedagógico, bem como quais desdobramentos podem ocorrer a partir deste quadro, referentes às condições oferecidas para o desenvolvimento psicológico das crianças, na educação brasileira contemporânea. A seguir, serão apresentados tópicos que fundamentaram as análises, iniciando por uma síntese da proposta de Ensino Fundamental de 9 anos.

\section{O Ensino Fundamental de 9 anos nos documentos oficiais}

A consulta aos documentos do Ministério da Educação (Brasil, 2003, 2004a, 2004b, 2006a, 2006b) que apresentam o novo EF, permite identificar que não se pretende meramente antecipar a entrada das crianças na escola obrigatória e/ou acrescer um ano em sua duração mínima; pretende-se construir um novo currículo para este segmento educacional. Do ponto de vista dos idealizadores do projeto, “(...) não se trata de transferir para as crianças de 6 anos os conteúdos e atividades da tradicional primeira série, e sim conceber uma nova estrutura de organização dos conteúdos" (Brasil, 2004b, p. 17).

Para materializar esta opção, propõe-se que, ao lado de investimentos em letramento e alfabetização, as escolas garantam uma escolarização enriquecida, sobretudo pela presença sistemática de atividades lúdicas. O seguinte excerto ilustra estas diretrizes, apresentando

o brincar como uma das prioridades de estudo nos espaços de debates pedagógicos, nos programas de formação continuada, nos tempos de planejamento; o brincar como uma expressão legítima e única da infância; o lúdico como um dos princípios para a prática pedagógica; a brincadeira nos tempos e espaços da escola e das salas de aula; a brincadeira como possibilidade para conhecer mais as crianças e as infâncias que constituem os anos/séries iniciais do ensino fundamental de nove anos. (Brasil, 2006b, p. 11-12).

Considerando-se que na fundamentação teórica referida pelos documentos destaca-se, no que diz respeito à Psicologia, a abordagem histórico-cultural, é possível dizer que esta ênfase na importância de que a atividade lúdica integre o currículo dos anos iniciais do EF faz sentido, já que as brincadeiras especialmente os jogos de faz-de-conta - são consideradas como atividades especialmente promissoras para criação de zonas de desenvolvimento proximal por Vygotsky (1994) e como atividade principal da infância por Leontiev (1978, 1988). Com os trabalhos destes autores, entendemos que esta atividade contribui para processos psicológicos fundamentais, especialmente a independência do campo perceptual imediato, a capacidade de operar no plano simbólico, a apropriação de formas culturais de relações e ações sobre o mundo, a linguagem e a imaginação.

Todavia, o contato regular com escolas permite afirmar que estes objetivos são bastante audazes, já que exigem mudanças amplas na cultura escolar. Como se sabe, de um modo geral, o EF tem se caracterizado por pouca afinidade com o que se pretende na nova proposta, a fim de garantir a constituição, nos aprendizes, de um

olhar aguçado pela sensibilidade, pela emoção, pela afetividade, pela imaginação, pela reflexão, pela crítica. Olhar que indaga, rompe, quebra a linearidade, ousa, inverte a ordem, desafia a lógica, brinca, encontra incoerências e divergências, estranha, admira e se 
surpreende, para então estabelecer novas formas de ver o mundo (Brasil, 2006b, p. 53).

Sem dúvida, mudanças deste quilate representam desafios e demandam investimentos significativos para que possam ser enfrentados pelas escolas e por suas professoras. Alguns destes desafios são bastante previsíveis: para atender ao que propõe o governo é necessário um trabalho consistente de fundamentação teórica e instrumental do corpo docente e das equipes técnicas, bem como a garantia de infra-estrutura e recursos materiais para sua execução. $\mathrm{O}$ desenvolvimento da pesquisa permitiu identificar sérias dificuldades nestes aspectos (Rocha, 2007). ${ }^{1}$ Mas, permitiu também identificar um outro tipo de desafio que se apresentou no ano de implementação do EF: os modos de compreensão das famílias das crianças sobre a proposta a que tiveram que aderir, pela obrigatoriedade da lei.

\section{MÉTODO}

O material exposto a seguir foi construído a partir de 58 entrevistas semi-estruturadas, feitas com familiares dos alunos de 6 anos (52 mães, 4 pais e 2 avós). Os primeiros contatos com as famílias ocorreram através de nossa participação em reuniões regulares das escolas, as reuniões de pais e mestres. Estes contatos permitiram apresentar a pesquisa, obter consentimento dos pais ou responsáveis para seu desenvolvimento ${ }^{2}$ e anunciar o agendamento das entrevistas. As entrevistas foram, posteriormente, marcadas pelas professoras, através de bilhetes nos cadernos dos

Análises sobre os resultados das observações participantes e das entrevistas com as professoras são abordadas em outros artigos de nossa autoria, um deles já publicado (Rocha, 2007) e outro em fase de avaliação em periódico. Neles, são evidenciados o despreparo das escolas do ponto de vista das condições físicas e materiais para a implementação do novo sistema educacional e os problemas apontados pelas professoras quanto às orientações que (não) receberam sobre o currículo a ser construído para os primeiros anos. Analisa-se, também, nestes textos, as sérias dificuldades encontradas com relação à inclusão de atividades lúdicas no cotidiano escolar advindas de um conjunto de fatores de natureza diversa e a experimentação de angústia por parte das professoras em relação ao modo pelo qual se efetivava a implementação deste modelo de ensino nas escolas municipais estudadas.

2 O projeto de pesquisa foi aprovado pelo Comitê de Ética e todos os participantes assinaram Termo de Consentimento Livre e Esclarecido, autorizando seu desenvolvimento. alunos, aos quais os pais, mães ou responsáveis respondiam concordando com a data e horário marcados ou indicando impossibilidade de comparecer à escola, local em que os encontros se realizaram. Sendo assim, do universo de pais das 8 turmas foram entrevistados aqueles que manifestaram interesse e disponibilidade para participarem da pesquisa.

O número de participantes variou (de 1 a 4) a cada encontro. Em função da diferença do número de participantes, a duração das entrevistas foi também bastante variada. Entretanto, quase nunca foram rápidas, durando $1 \mathrm{~h}$ e 30 , em média. A maioria dos participantes mostrou-se bastante interessada em abordar o assunto em pauta, relatando com detalhes os significados das novas experiências escolares para si, para as crianças e para outros membros da família, revelando-se ótimas informantes. Durante as entrevistas, os temas abordados foram: levantamento de informações sobre freqüência ou não dos novos alunos em instituições de Educação Infantil no(s) ano(s) anterior(es), como e por quem os pais foram informados sobre o novo Ensino Fundamental, como compreenderam e como avaliaram esta nova lei, como compreendem e avaliam a forma como a vida escolar das crianças de primeiros anos está sendo construída, como e por quem as crianças foram informadas sobre sua ida para os primeiros anos, como reagiram a isto e, por fim, como as crianças estavam enfrentando sua experiência escolar.

As entrevistas foram gravadas em áudio e transcritas na íntegra. Posteriormente, foram feitas análises qualitativas sobre o material, a partir da categorização dos temas mais recorrentemente abordados pelos entrevistados.

Antes de passarmos à apresentação dos resultados e de suas análises, importa dizer que as escolas focalizadas atendem, predominantemente, a crianças de classes populares, residentes em bairros de uma região da periferia do município em que a pesquisa se desenvolveu. Em termos descritivos, dados censitários (IBGE, 2000) registram que 30 a 47,6\% dos responsáveis pelos domicílios têm menos de 8 anos de instrução e de 8 a $16 \%$ não têm quaisquer rendimentos. Em termos dos índices de exclusão social, esta região ocupa a $2^{\mathrm{a}}$ posição na escala que identifica as parcelas da população mais expropriadas de seus direitos sociais no município. As escolas e suas professoras, portanto, conviveram e trabalharam, predominantemente, com pessoas pobres, pouco escolarizadas e excluídas socialmente. 


\section{RESULTADOS E DISCUSSÃO}

As análises desenvolvidas sobre o material empírico evidenciaram grande regularidade nos modos pelos quais as famílias interpretaram e avaliaram o primeiro ano escolar de suas crianças. O conteúdo das entrevistas foi categorizado em: (i) explicações e expectativas construídas sobre o primeiro ano do EF, (ii) apreensões em relação à vida escolar das crianças e (iii) avaliações das famílias sobre o trabalho pedagógico desenvolvido em 2006.

\section{Explicações e expectativas sobre o primeiro ano do EF}

A maior parte das famílias surpreendeu-se, ao final de 2005, quando foi matricular pela primeira vez ou re-matricular suas crianças em turmas de pré, na EI. Neste momento, tomaram conhecimento da nova lei e foram informadas que meninos e meninas desta faixa etária seriam encaminhados para as escolas de EF. Poucas mães (2) obtiveram esta informação através de jornais (televisivo e impresso) e uma delas foi informada na escola municipal em que trabalha.

Algumas reuniões foram realizadas por algumas EMEIs (escolas municipais de educação infantil) e EMEFs (escolas municipais de ensino fundamental) com objetivo de fornecer esclarecimentos sobre as novas regras. Mas, dada a precariedade das informações que as próprias escolas tinham naquele momento (final de 2005 e início de 2006), muitas dúvidas e explicações peculiares sobre o novo $\mathrm{EF}$ acompanharam as famílias ao longo de 2006. Algumas dessas dúvidas e explicações estão representadas nos trechos das entrevistas (realizadas em outubro de 2006, portanto já tendo transcorrido mais da metade do ano escolar), transcritos a seguir.

\begin{abstract}
Sônia ${ }^{3}:$ Eu entendi que vai ter um ano a mais. Que era 8 e agora vai ser 9. Eu não entendi por quê. Eu queria entender mais um pouquinho o por quê, por que vai ter um ano a mais. Li [em jornal diário da cidade], mas não entendi muito bem o motivo, o por quê.
\end{abstract}

Cleuza: $O$ ensino do Brasil estava muito atrasado e teve que fazer um ano a mais para poder estar entrando um ano mais cedo, para não sair tarde também, depois. Ia ser mais produtivo para a criança também. Que dizem que nesta idade, é a melhor idade

3 Os nomes dos participantes são fictícios. para ela estar aprendendo as coisas. Aí, eu vim e matriculei ela aqui.

Marciely: O ensino fundamental começa
mais cedo, para acabar com 9 anos. Tem
todo um projeto pra isso, ainda em
encaminhamento. Até demorou um pouco no
Brasil. Porque isso, nos países de primeiro
mundo, já fazia, o ensino fundamental até
com 8, né? Até mesmo em Cuba... Lá, já há
muitos e muitos anos... No Brasil, demorou
muito. Porque é um período em que a
criança tem um aprendizado melhor. Porque
se for ver bem, ela já entra na escola cedo,
porque as mães já mandam os bebês com 4
meses na escola. Quatro meses, fica até 7,
né? Quando chegar no fundamental, ele não
vai querer estudar mais. Já tá cansado.

As informações lacunares e contraditórias oferecidas nas unidades educacionais permitiram a construção destas versões, pelos familiares. Por vezes, ocorreu a produção de explicações opostas sobre o novo sistema de ensino, com relação à sua duração. Algumas mães entenderam que as crianças terminariam o EF mais cedo (e aprovaram, então, o projeto); outras entenderam exatamente o contrário: que as crianças concluiriam seus estudos um ano mais velhas do que seria esperado no sistema educacional anterior (e, nestes casos, desaprovaram o projeto).

As dúvidas referiram-se também ao futuro escolar próximo das crianças. Perguntas como "Primeiro ciclo é o mesmo que primeira série?" ou "E o segundo ciclo é a segunda série mais forte?" "Do Primeiro Passo vai para a primeira série ou do Primeiro Passo vai para a segunda série? ${ }^{4}$ " e outras bastante similares eram feitas pelos participantes das entrevistas. Segundo disseram as professoras, as reuniões que foram realizadas com os pais, mães ou responsáveis e o início do ano escolar foram vividos com grande desconforto por todos os profissionais das escolas, já que tinham, eles próprios, mais dúvidas do que certezas em relação ao futuro acadêmico de seus novos alunos e sobre o que deveriam fazer com e para eles.

É importante dizer que a desinformação sobre os objetivos pedagógicos do novo $\mathrm{EF}$ não foi um problema local destas escolas. Gorni (2007), em pesquisa feita no Paraná, concluiu que também lá muito pouco se sabia a respeito da proposta e aponta para a "evidente precocidade da implantação [do novo

\footnotetext{
4 Primeiros Passos foi o nome adotado por algumas escolas municipais para se referirem ao primeiro ano do primeiro ciclo do novo modelo de EF.
} 
$\mathrm{EF}$ ] de forma ampla e generalizada, antes que fossem garantidas as condições de preparação das respectivas escolas e professores" (p. 78).

Embora houvesse um esforço constante das professoras e dos especialistas por fazerem parecer que estavam seguros em relação aos objetivos que buscariam cumprir, ao currículo que operacionalizariam e aos critérios de progressão escolar dos alunos, em algumas situações as famílias chegaram a perceber que os educadores não tinham respostas claras e embasadas para thes dar.

Cleonice: Perguntei para a Vera [professora]: $e$ o ano que vem, vai dar continuidade ao trabalho? Ela falou assim "Pode ser... Depende". "É para ser assim". Então, acho que ela também não sabe. Já que eles inventaram, implantaram isto, eles têm que estar preparado para o futuro.

Laysse: Eles tiveram a idéia, mas não tem nada pronto. Joga os professores e: “ó, se vira!!”. Por trás de tudo isso, tem politicagem. Na creche mandaram uns papéis falando que ia mudar. A diretora começou a ir nas reuniões e voltava dizendo: "Acho que vai ser assim, acho que vai ser assado". Tinha sempre o acho na frente.

Em outras situações, os familiares não chegaram a ter esta percepção e assumiram como sua a responsabilidade de não terem compreendido o que estava sendo definido no jogo escolar.

\begin{abstract}
Cássia: Na última reunião, final do ano, que eu fiquei sabendo. Para mim, ele [o filho] estava fazendo o pré. Ainda falei pra ele: "começa a pegar firme agora [outubro], porque ano que vem você vai para a primeira série". Aí, as meninas falaram: "mãe, o William já tá na primeira série”. Só que eu não entendia esta mudança. Agora que 'caiu a ficha'. "Caramba! Então ele tá na primeira série!”. Explicar, me explicou [a professora]. É minha cabeça que não deu, que falhou. Eu achava que era um pré. Então, eu deixei ele faltar várias vezes. Agora que eu vi a conseqüência.
\end{abstract}

Mas, mesmo sem terem os elementos necessários para explicarem e compreenderem o que estava proposto, a recepção da nova lei foi predominantemente positiva (apenas 2 mães relataram que prefeririam que os filhos estivessem na EI). $\mathrm{O}$ termos mais usados para qualificar positivamente a matrícula no primeiro ano do EF foram: "aprendendo", "aprendizado", "aprende", "estudar", "estudo", "produtivo", "crescimento", "criança mais ativa", "eles vai mais pra frente" "desenvolvendo tudo mesmo". Ou seja, houve por parte dos familiares a tendência de explicar o novo sistema de ensino entendendo que as novas experiências escolares trariam importantes contribuições para o processo de aprendizagem de suas crianças. Seguramente, não estavam se referindo a quaisquer aprendizagens e sim àquelas tipicamente relacionadas à escolarização; mais precisamente, os entrevistados demonstraram terem construído fortes e precisas expectativas de que a freqüência antecipada das crianças às escolas só poderia ter um sentido e uma meta: alfabetizá-las. Estas expectativas ficam mais claras quando analisamos as apreensões que relataram ter experimentado e as avaliações que realizaram sobre o trabalho pedagógico, abordadas nos próximos tópicos.

\section{As apreensões em relação à vida escolar}

Com exceção de uma mãe, todos os adultos afirmaram terem tido preocupações em relação ao primeiro ano de vida escolar. Segundo disseram, as grandes fontes destas preocupações referiram-se a dois temas: alfabetização e violência. Pode-se sintetizar assim as dúvidas que tiveram: os novos alunos iriam acompanhar os conteúdos pedagógicos - leia-se alfabetização - que seriam trabalhados nas suas turmas? Sendo as crianças tão pequenas e menores em relação aos outros alunos, poderiam sofrer algum tipo de agressão, especialmente por parte dos colegas maiores e mais velhos?

As apreensões em relação ao segundo tema (violência) foram mais rapidamente atenuadas ou superadas pelas informações dadas pelas escolas: as crianças menores teriam seus horários de merenda e de intervalo separados dos horários das crianças maiores e estariam, assim, protegidas.

Com relação às apreensões sobre a alfabetização, o material empírico mostrou que para muitas famílias elas eram anteriores ao ingresso das crianças nas EMEFs e não desapareceram ao longo de 2006. Para compreender melhor esta questão, algumas informações sobre a história de escolarização das crianças são importantes.

Os adultos entrevistados informaram que a maioria dos novos alunos $(72,1 \%)$ havia frequientado instituições de EI antes da experiência escolar no EF. Desta porcentagem, 44,6\% freqüentaram pré-escolas públicas, $17,2 \%$ freqüentaram pré-escolas particulares e $10,3 \%$ freqüentaram instituições nãogovernamentais. Para $27,9 \%$ das crianças o ingresso no primeiro ano do EF representou sua primeira experiência escolar. Segundo os familiares, este fato 
deveu-se à imensa dificuldade de conseguirem vaga na rede pública para as crianças menores 5 . A dificuldade em conseguir vagas na EI levou parte dos familiares entrevistados a fazer investimentos pessoais e financeiros anteriores e/ou paralelos ao ingresso das crianças em alguma instituição educacional, a fim de contribuir para o bom desempenho escolar futuro. Os seguintes trechos exemplificam estes investimentos.

Cleide: Eu ensinei tudo em casa. A fazer o nome, os números.

\begin{abstract}
Maria: Antes dela ir na creche, eu tinha ponhado com uma mocinha pra ensinar. E aquela menina ensina maravilhosamente bem. Ela [neta] falou assim: "Ah, vovó, põe eu na escola”. Eu pus. Na Cecília. E não foi que ela aprendeu mesmo? Lá que ela desenvolveu, porque na creche, quando consegui vaga, só brincava, não estudava quase nada.
\end{abstract}

Disseram as entrevistadas que estes investimentos permitiram às crianças entrarem na escola sem ter a "mão dura" para a escrita, "já sabendo alguma coisa". A expressão "já sabendo alguma coisa" pode parecer bastante genérica, mas as análises do material permitem afirmar que esta expressão refere-se com precisão a conteúdos específicos: "dominar $o$ abecedário", "fazer o alfabeto", "soletrar as letras todinhas", "decorar letras", "conhecer famílias silábicas", aprender a "escrever o próprio nome e o nome dos irmãos", escrever "palavras $e$ ter conhecimento dos números".6. Para obterem estes resultados, algumas mães adquiriram material tipicamente escolar como cadernos, lousa e giz, nos quais e com os quais passavam "liçõezinhas" para seus filhos e filhas.

Estas informações nos permitem compreender que a generalizada/freqüente suposição de que as famílias de grupos populares têm pouca preocupação e interesse em relação às aprendizagens escolares precisa ser, no mínimo, problematizada. A porcentagem de arranjos como contratação de

5 Estas informações são consubstanciadas por estatísticas oficiais: os bairros onde residem os participantes compõem uma região em que a insuficiência de recursos públicos para atender à demanda por creches e educação infantil está no segundo nível mais grave do município (IBGE, 2000).

6 Linhares (2008) ajuda-nos a entender que o uso de expressões como "já sabendo alguma coisa", "não sabiam nada" por grupos populares em geral refere-se a uma crescente valorização dos conhecimentos escolares e progressiva desqualificação dos conhecimentos adquiridos nas famílias. educadoras leigas $(13,8 \%)$ e mães que ensinam o que sabem para preparar seus filhos $(32 \%)$ evidencia a ocorrência de práticas de superinvestimento e sobreescolarização, também apontadas em outros trabalhos (como, por exemplo, em Thin, 2006 \& Vianna, 2005).

Se não foram todos os adultos que colocaram em funcionamento estas estratégias, todos os entrevistados (com exceção de uma mãe, como já dito) relataram preocupações quanto ao futuro desempenho escolar das crianças, preocupações estas, freqüentemente, compartilhadas pelos próprios filhos/filhas ou netos/netas. O medo de que as crianças não fossem "acompanhar", de que as experiências educacionais na EI não seriam suficientes para habilitá-las ao estudo, de que as professoras fossem "pegar pesado" e "já pegar o trem, mesmo" foi vivido com regularidade a partir do momento da matrícula no EF.

O último tópico a ser abordado - as avaliações feitas pelas famílias sobre as experiências escolares concretamente vividas - traz mais informações e permite aprofundar a compreensão sobre suas relações com o EF de 9 anos. Com as análises, poderemos entender que os significados produzidos sobre o ingresso das crianças nas novas escolas traduziram-se em expectativas referentes à alfabetização (como visto até este ponto) e também em oposição a outras atividades que compuseram o cotidiano educacional, avaliadas consistentemente de modo negativo pelos adultos entrevistados; de forma especial, justamente as atividades que os idealizadores do projeto desejam ver incorporadas ao currículo, revolucionando a cultura escolar: as atividades lúdicas. Vejamos, então, como os entrevistados se posicionaram sobre as práticas pedagógicas adotadas nas turmas de primeiro ano.

\section{As avaliações das famílias sobre o trabalho pedagógico desenvolvido em 2006.}

Lígia: Aí teve o problema da lição também. Eu perguntava: "Paula, cadê a lição?”. "Nós fez lição, mãe”. "Paula, mas cadê a lição? A gente abre este caderno, não tem nada!!”. Eu falei pra ela assim: "ai, sua professora não está ensinando ninguém”. Eu xinguei: "sua professora é burra!!". Mandei um bilhetão enorme para a professora. Eu queria saber. Aí a professora mandou outro bilhete, explicando o negócio da escola de 9 anos. Ai, meu deus. Ela falou que as crianças entravam agora com 6 anos, que era a escola de 9 anos, que tinha agora um projeto, que era mais devagar mesmo. Eu falei: "Então, peraí, é como se fosse uma creche?!? Porque, pra mim, isto aqui está 
igual a uma creche!! Parece um prezinho. Está aprendendo o que aprende numa creche, num prezinho. Era para aprender a escrever, a ler, todo aquele processo". (...) Aí, ela [a professora] ficou conversando comigo, tentando enfiar isso na minha cabeça.

Maria: Ela [a professora] não trabalhou com família, ela trabalhou $a-e-i$ - $o$ - $u$. Não fixou aquilo, pulou pro ba-be-bi-bo-bu. Não juntou o a-e-i-o-u com o ba-be-bi-bo-bu. Colocou o a-e-i-o-u com o ba-be-bi-bo-bu e com o la-le-li-lo-lu. Aí fez uma salada! Eu achei que não fixou. Ela pegou uma família do início e uma do final. Elas [as crianças] não conheciam a família do la!. Ela [a filha] tem uma dificuldade enorme de fazer o casalzinho: $b$ com a, ba... E nós tamos no final do ano! Já era pra saber! Isto é uma meta que a professora tem que ter. Como uma criança de primeira série, você mandar escrever CLEODETE, você mandar escrever CASA? Porque é S com som de Z. Confunde! São palavras que eu to achando que são muito avançadas, que não tem lógica: se não aprendeu que o $S$ com A dá SA, como que vai colocar o $S$ com A, que dá ZA? Acho que deveria ter uma meta pra ensinar, uma meta dos professores para que não venha a confundir o som das palavras.

Os trechos acima foram escolhidos por representarem os aspectos focalizados pelos adultos ao fazerem avaliações sobre o trabalho desenvolvido pelas professoras: a quantidade de tarefas registradas nos cadernos escolares (seguramente o vetor principal para as avaliações) e a qualidade das tarefas, como Maria analisa, minuciosamente (avaliações deste tipo não foram tão frequientes; nem por isso são menos importantes). A quantidade de tarefas é usada pelos pais para monitorarem o ritmo do trabalho pedagógico e suas repercussões nos processos psicológicos de desenvolvimento, aprendizagem e motivacionais das crianças (repercussões estas identificadas concretamente em seus filhos ou supostas, como probabilidade). Dizem os entrevistados que consideram a experiência escolar como "uma coisa lenta", pois a produção de "uma folha não é proporcional às 4 horas" que ficam na escola e que as professoras deviam dar "uma puxadinha a mais" na aprendizagem, "pegar mais no pé”, "fazer a cabeça ir trabalhando".

O trabalho pedagógico de outras unidades educacionais foi, por vezes, tomado como referência para as avaliações, especialmente nos casos de algumas crianças que haviam freqüentado escolas estaduais e, posteriormente, foram transferidas para as escolas municipais pesquisadas. Nestes casos, algumas mães disseram que:

Gisele: Eles tinham muita atividade na outra escola. Muita. Toda semana tinha lição de casa, terça-feira. Era lotado. Nas férias, então, veio um monte de lição. Era ótimo.

Suely: Na outra escola, ele tinha um caderninho de tarefa, você via até nota. $E$, de repente, ficou uns 3 meses sem nenhum tipo de informação.

Os modos como as professoras organizaram o trabalho pedagógico foram apontados como geradores de impactos negativos no processo de aprendizagem, levando algumas mães e pais a acharem que suas crianças começaram a "regredir na escrita", terem "recaídas", terem "branco", não lembrarem mais nem "como escrevia o próprio nome" e não estarem "desenvolvendo nada, aprendendo nada". Preocuparam-se, ainda, com repercussões no processo motivacional das crianças para aprender indicando, em alguns casos, que "ela se decepcionou”, “o sonho dela é levar lição para casa e não traz nada, não chega caderno em casa!", "ela sente falta de fazer mais coisas, ter mais tarefas”. Algumas mães disseram que procuraram compensar esta reduzida ou ausente prática de tarefas para casa com atividades produzidas por conta própria.

Fabiana: (...) ela chega em casa, já querendo fazer coisa, já procura o materialzinho dela. E começa a escrever $e$ me perguntar como se escreve tal coisa. Até continha ela faz.

Wilma: (...) fiquei super preocupada dele se decepcionar. Eu acho que ele gostaria de estar aprendendo mais, porque ele passa o dia inteiro com lápis e caderno na mão. E, aí, eu passo tarefa pra ele.

Nem todos os entrevistados se posicionaram desta forma e 18 deles $(31 \%)$ avaliaram o trabalho de maneira positiva, dizendo estarem satisfeitos com o primeiro ano do EF. Mesmo nestes casos, foram predominantemente apontadas as mesmas categorias que serviram de base para os posicionamentos negativos: a quantidade de tarefa, as práticas de alfabetização, os avanços das crianças nesta esfera do conhecimento.

Sendo assim, não parece haver dúvidas de que, para os familiares, boas professoras são aquelas que 
investem de modo sistemático, rigoroso e em alta frequiência na aprendizagem de determinados conteúdos, dentre os quais a alfabetização operacionalizada nas formas mais tradicionais, como soletrar, decorar, copiar etc. - é vista como prioridade máxima e os conhecimentos matemáticos como campo também importante, embora secundário.

Dados os objetivos deste trabalho, antes de passarmos às considerações finais é necessário analisar mais uma questão: os modos como os familiares avaliaram a incorporação das atividades lúdicas no cotidiano escolar. Vejamos alguns exemplos.

Gisele: O primeiro dia que ele chegou da escola, eu perguntei: "Cristian, o que que você fez hoje?" "Nada, mãe, eu brinquei". "Como assim, eu brinquei? O que você fez. no caderno?”. "Mãe, lá não tem caderno”. "Como que não tem caderno?. Ficou só brincando? Não está certo”.

Flaviana: "O que que você fez na escola ontem?". "Ah, eu assisti DVD, brinquei...”. Ué?!? Aí eu fiquei meio cabreira também.

Dirce: Eu falei pra Lauren: "você não faz lição? O que você faz lá? Você não tá fazendo nada?". "Ah, a gente leu o texto, fez o desenho. Fez a história. A gente brincou". Eu falei: "mas vai ficar só nisso? Lendo histórias? Brincando?”.

Os investimentos em outras práticas que não fossem alfabetização foram olhados com certa tolerância (em poucos casos) e com desconfiança, menosprezo ou oposição (na maior parte das vezes). Ou seja, embora em alguns momentos os pais tivessem uma atitude mais compreensiva em relação às brincadeiras infantis, em geral esta compreensão foi possível quando as atividades de alfabetização estavam sendo contempladas, concomitantemente à atividade lúdica e de modo privilegiado. Em geral, quando as crianças informavam aos pais sobre seu prazer em ter brincado e/ou sobre seus desejos de brincarem mais nas escolas, os adultos esforçaram-se por sinalizar-lhes que a escola não era lugar para brincar, buscando convencê-las das vantagens de terem crescido e por estarem "freqüentando a primeira série" do EF. Desde oposições frontais (do tipo "pó parar com essa história de parquinho") até formas mais condescendentes ("não é todo dia [que pode brincar com] boneca"), o fato é que muitos pais disseram às crianças frases como: "Você tem que estudar, que aprender", "você não é mais tão criança como antes", "agora você tem mais um pouco de responsabilidade", "agora você já está mais homenzinho", "tem que fazer coisas mais sérias", buscando convencê-las de que elas se tornaram mais "importantes", "grandonas". Estes esforços de convencimento nem sempre foram acolhidos sem resistências por parte das crianças.

Dayse: Ela queria muito ir para o prezinho, prezinho era tudo para ela. Então, ela fala "Ah, mãe, mas e o prezinho? Eu não vou brincar naquela casinha?".

Gabriela: Falaram que a Prefeitura ia enviar brinquedos aqui. Acabou o ano $e$ nada aconteceu. Ele falou: "Tá vendo mãe, ele mentiu [diretor da escola]”. Eu falei: "Eles não teve verba para mandar os brinquedos". "É, mas agora acabou o ano, mãe. Acabou o ano". Estas coisas de escorregador, que ele quer. Eu falei: "Vinícius, agora aumentou um ano. E você não é mais tão criança como antes”. Eu procuro explicar assim. Às vezes ele fala: "Ah, mas é chato. Lá na EMEI era mais legal". "Mas agora, aumentou a sua responsabilidade. Agora você tem mais um pouco de responsabilidade".

\section{CONSIDERAÇÕES FINAIS:}

O desenvolvimento da pesquisa possibilitou identificar que frente à implementação do Ensino Fundamental de 9 anos, as famílias construíram explicações, expectativas, apreensões e avaliações sobre os objetivos deste novo modo de funcionamento da educação básica a partir de um tema nuclear: a alfabetização. As lacunas/contradições nas informações dadas pelas escolas sobre os objetivos pedagógicos do primeiro ano foram preenchidas - sem muitas dificuldades - pelos adultos com palavras que se incluem, tradicionalmente, neste tema: cadernos, letras, sílabas, palavras, etc.

Podemos, por isso, dizer que os adultos operaram segundo a "lógica da eficácia". Thin (2006), trabalhando com os conceitos bourdieusianos, esclarece que a "lógica da eficácia" sintetiza a tese de que o sentido da escolarização para os grupos de baixa renda reside, fundamentalmente, nas possibilidades que a escola pode viabilizar de estabilidade ou de ascensão social para seus alunos; esta potencial viabilização só será concretizada (do ponto de vista destes grupos) se a escola garantir aos escolares a apropriação dos conhecimentos específicos. No caso dos anos escolares iniciais, estes conhecimentos são a 
alfabetização e o domínio das competências em cálculo. Em razão disso,

todas as atividades que parecem afastar as crianças das aprendizagens ditas fundamentais, e que não parecem contribuir para a melhoria dos resultados escolares, são mais ou menos suspeitas aos seus olhos [das famílias dos alunos]. Aparecendo como inúteis, incoerentes com relação a esses objetivos, elas só podem ser perda de tempo. (Thin, 2006, p. 221).

No caso das mães, avós e pais a quem se deu voz neste trabalho, as suspeitas recaíram, prioritariamente, sobre a atividade lúdica. Da perspectiva deles, fizeram as matrículas de suas crianças não na "escola pensada pelo governo", mas na "escola que ensina a ler e a escrever". Assim, no sentido oposto dos idealizadores do projeto, esperavam/exigiam que fosse garantido aos novos/as alunos/as exatamente a aprendizagem de conteúdos e atividades da "tradicional primeira série" do EF, que os documentos oficiais orientavam que fosse "extinta". Os familiares participantes desta pesquisa, não viram e não legitimaram "o lúdico como um dos princípios para a prática pedagógica" e/ou a importância da "brincadeira nos tempos e espaços da escola e das salas de aula" (Brasil, 2006b, p.11-12).

Se, por um lado, o registro destas formas pelas quais os grupos populares representam a experiência de escolarização e avaliam sua proficuidade (valorizando determinados tipos de conteúdos e práticas e rechaçando outros/as), não é propriamente uma novidade (como vimos, já vêm sendo identificadas em estudos anteriores), não se pode esquecer que há um fato novo: elas se instalaram um ano mais cedo em relação ao momento em que comumente ocorriam. De um modo geral, podemos ter como hipótese que se em 2006 as crianças tivessem sido matriculadas nas EI, conforme era o esperado pelas famílias, elas não teriam ouvido de seus familiares as prescrições que foram verbalizadas para indicar que um novo período do desenvolvimento estava sendo inaugurado e que as brincadeiras não seriam parte importante deste período.

$\mathrm{O}$ quadro geral sobre as representações relativas à atividade lúdica por parte dos familiares (recorte feito neste trabalho) é merecedor de atenção e cuidados por exercer inevitáveis pressões sobre a construção do currículo para os anos iniciais de escolarização obrigatória, podendo ter importantes repercussões no trabalho pedagógico, no qual o lugar para as brincadeiras seja cada vez mais marginal. Estando correta esta hipótese, podemos argumentar que, dependendo do modo como estas questões forem trabalhadas (pelas escolas, pelas professoras, pelo poder público), com a implementação do novo EF de 9 anos pode estar em construção a produção de mudanças nos significados e tempos da infância.

Assim, não parece excessivo levantar preocupações com as repercussões destas tendências para o desenvolvimento psicológico, sobretudo para os processos já apontados como especialmente possíveis/importantes de se desenvolverem neste tipo de atividade que ainda compõe a infância contemporânea.

Entretanto, convém lembrar que estes resultados se referem ao ano exato de implementação do projeto e que reformas ou mudanças no sistema educacional devem ser acompanhadas e avaliadas por um período maior de tempo para que se possa identificar de que modos se consolidam (ou não) no interior da cultura escolar.

O desenvolvimento da pesquisa permite uma última consideração: o material empírico evidencia que nem sempre as pessoas pobres atuaram a partir de sentimento emergente de restrição (conforme Lareau, 2007) na relação com profissionais de instituições dominantes. Ainda que tenhamos observado que nas reuniões formais da escola predomina uma postura de timidez e silêncio por parte das famílias em relação àquilo que as professoras dizem/informam (bastante contrastante com a riqueza das verbalizações nas entrevistas) não se pode dizer que tenham sido passivos e/ou uniformemente receosos em indagar/questionar/opor-se às professoras. Bilhetes nos cadernos, solicitações de reuniões-extras, consultas/exigências à Secretaria de Educação e ao Conselho Tutelar, foram maneiras encontradas por algumas famílias para fazer frente àquilo que consideravam inadequado nos procedimentos das escolas e/ou professoras. Estes fatos apontam para mudanças nos modos como os grupos populares se relacionam com a escola e para a relevância de pesquisas que cuidem de registrá-las e analisá-las. Uma hipótese possível é a de que a divulgação sistemática pela imprensa dos resultados dos exames nacionais de desempenho (SAEB, por exemplo), dando visibilidade às dificuldades que o sistema de ensino público enfrenta e às preocupantes defasagens na aprendizagem de leitura, escrita e cálculo dos alunos brasileiros, venha desempenhando um papel de alertar os pais sobre o fracasso das escolas em garantir a proficiência de grande parte da população nestes conhecimentos e de, como 
conseqüência, impelindo-os a uma posição de vigilância sobre os procedimentos pedagógicos que compõem o cotidiano escolar de seus filhos.

A partir destas considerações só nos parece possível encerrar este trabalho com perguntas: como tem ocorrido a continuidade de implementação do EF de 9 anos nestas escolas? A experiência maior e as oportunidades de estudo/clarificação sobre os objetivos do EF de 9 anos permitirão às professoras e às escolas encontrarem argumentos para explicar às famílias a importância de outras atividades que não só as de alfabetização e provocar mudanças em suas avaliações? As respostas a estas perguntas só serão possíveis com a continuidade do trabalho de campo e com a oportunidade de diálogo com outros trabalhos de pesquisa que venham sendo realizados sobre este tema.

\section{REFERÊNCIAS}

Brasil (2003). Ministério da Educação e Cultura. Secretaria de Educação Básica. Política Nacional de Educação Infantil: o direito das crianças de zero a seis anos à Educação. Brasília.

Brasil (2004a). Ministério da Educação. Secretaria de Educação Básica. Ampliação do Ensino Fundamental para Nove Anos. Relatório do Programa. Brasília.

Brasil (2004b). Ministério da Educação. Secretaria de Educação Básica. Ensino Fundamental de Nove Anos. Orientações Gerais. Brasília.

Brasil (2006a). Ministério da Educação. Secretaria de Educação Básica. Ampliação do Ensino Fundamental para Nove Anos. Terceiro Relatório do Programa. Brasília.

Brasil (2006b). Ministério da Educação. Secretaria de Educação Básica. Ensino Fundamental de Nove Anos: orientações para a Inclusão da Criança de Seis Anos de Idade. Brasília.

Gorni, D. A. P. (2007). Ensino Fundamental de 9 anos: estamos preparados para implantá-lo? Ensaio: avaliação de políticas públicas Educacionais. 54(15). Recuperado em 10 de abril de $2008 \mathrm{em} \mathrm{http://www.scielo.br/scielo}$

Lareau, A. (2007). A Desigualdade invisível: o papel da classe social na criação dos filhos em famílias negras e brancas. Educação em Revista. Belo Horizonte, 46. Recuperado em 12 de fevereiro de $2008 \mathrm{em} \mathrm{http://www.scielo.br/scielo.}$

Leontiev, A. N. (1978). O Desenvolvimento do Psiquismo. (M. D. Duarte, Trad.). Lisboa: Horizonte Universitário. (Original publicado em 1972).

Leontiev, A. N. (1988). Os Princípios Psicológicos da Brincadeira Pré-escolar. Em Vigotskii, L. S., Luria, A. R. \& Leontiev, A. N. Linguagem, Desenvolvimento e Aprendizagem (pp.59-83) (M. P. Villalobos, Trad.). São Paulo: Ícone.

Linhares, E. F. (2008). Escravos na roça, anjos na escola. Revista Tempo Social. 1(20). Recuperado em 14 de novembro de 2008 em http://www.scielo.br/scielo.

Rocha, M. S. P. M. L (2007). O Ensino de Psicologia e a Educação Infantil: a nova política pública para a Educação Infantil e o Ensino Fundamental e suas possíveis repercussões para o desenvolvimento psicológico infantil. ETD - Educação Temática Digital, Campinas, v. 8, p. 266-277, jun.

Thin, D. (2006). Para uma análise das relações entre famílias populares e escola: confrontação entre lógicas socializadoras. Revista Brasileira de Educação. 32(11). Recuperado em 14 de fevereiro de $2008 \mathrm{em} \mathrm{http://www.scielo.br/scielo}$

Vianna, M. J. B. (2005). As práticas socializadoras familiares como locus de constituição de disposições facilitadoras de longevidade escolar em meios populares. Revista Educação e Sociedade, 90(26). Recuperado em 14 de novembro de 2008 em http://www.scielo.br/scielo

Vygotsky, L. S. (1994). A Formação Social da Mente. (J. Cipolla Neto, L. S. M. Barreto, S. C. Afeche Trads.). São Paulo: Martins Fontes.

Recebido em 18/11/2008 Aceito em 30/06/2009 